\title{
Effects of Synthetic Pseudoceramides on Sphingosine Kinase Activity in F9-12 Cells
}

\author{
You-Xun Jin ${ }^{1}$, Kyong-Oh Shin ${ }^{1}$, Myung-Yong Park ${ }^{1}$, Shin-Hee Lee ${ }^{2}$, Byeong-Deog Park ${ }^{2}$, Seikwan Oh ${ }^{3}$, \\ Hwan-Soo Yoo ${ }^{1}$ and Yong-Moon Lee ${ }^{1, *}$ \\ ${ }^{1}$ College of Pharmacy, Chungbuk National University, Cheongju 361-763, \\ ${ }^{2}$ Neopharm Co. Ltd., Daejeon 305-510, \\ ${ }^{3}$ College of Medicine, Ewha Womens University, Seoul 158-710, Republic of Korea
}

\begin{abstract}
Sphingosine kinase (SPHK) has a central role to control cell death and cell proliferation, which is suggested as a sphingolipid rheostat by regulating the levels between ceramide and sphingosine 1-phosphate (S1P). Therefore, physiological regulators of SPHK will be a good candidate to develop a new targeted drug. For this purpose, a series of synthetic pseudoceramides were tested by SPHK assay either cell-based or cell-free system. K10PC-5 strongly inhibited SPHK, while K6PC-5 activated SPHK in cell-free system. Specifically, K6PC-5 activated SPHK under the co-treatment with $50 \mu \mathrm{M}$ dimethylsphingosine (DMS), a SPHK inhibitor. Collectively, we developed a simple SPHK assay system to find SPHK regulatory pseudoceramide compounds, K10PC-5 and K6PC-5 which may be useful to cancer treatment or immune regulation like FTY720, a synthetic sphingolipid mimetic compound.
\end{abstract}

Key Words: Pseudoceramide, Sphingosine kinase, F9 cells, Assay system

\section{INTRODUCTION}

Sphingosine kinase (SPHK) phosphorylated sphingosine to yield sphingosine 1-phosphate (S1P) which is a bioactive autocrine lipid as it binds to five different G-protein-coupled S1P (S1P1-5) receptors to elicit diverse biological responses (Lee et al., 1996). The produced S1P in mammalian cells is shortlived, due to rapid degradation by S1P lyase and dephosphorylation by S1P phosphohydrolases (Pyne and Pyne, 2000).

However, S1P has emerged as an enigmatic lipid which is implicated in both extracellular and intracellular signaling processes (Hla et al., 2001). S1P has been shown to be secreted into blood stream from platelets, red blood cells (RBCs) or vascular endothelial cells, and binds to S1P receptors on the surface of vascular endothelial cells, triggering such cellular processes as cell differentiation, migration, and mitogenesis (Maceyka et al., 2002). In addition, S1P also worked as a lipid second messenger participating in signaling cascades leading to cytoskeleton changes, motility, release of intracellular calcium stores, and cell protection from apoptosis (Kluk and Hla., 2002; Spiegel et al., 2002; Olivera et al., 2003; Watterson et al., 2003). Whether acting intracellular or extracellular, S1P is generated from phosphorylation of sphingosine by SPHK Therefore, the enhanced production of S1P in biological sys- tems through an increased SPHK activity has become an interesting research subject.

The ceramide-S1P rheostat theory has been suggested to determine the cell fate such that the intracellular concentration ratio of ceramide to S1P determines whether a cell proliferates or undergoes apoptosis (Spiegel et al., 2002). Ceramide is produced by hydrolysis of sphingomyelin in response to stresses, including exposure to chemotherapeutic drugs and induces apoptosis through multiple cell death signaling pathway (Hannun and Obeid, 1995; Ogretmen and Hamun, 2001; Johnson et al., 2002). Alternatevely, ceramide can be additionally hydrolyzed by ceramidase to produce sphingosine. Sphingosine is then rapidly phosphorylated by SPHK to produce S1P. Ceramidase and SPHK are activated by a number of growth factors and intracellular oncoproteins, leading to rapid increases in the intracellular S1P and concurrent depletion of ceramide. This situation promotes cell proliferation and inhibits apoptosis in tumor cells. Therefore, SPHK enzyme provides a potential target for the development of new anticancer drug (Claus et al., 2000).

There are limited regulators of sphingolipid-metabolizing enzymes, and therefore pharmacological regulation of sphingolipid metabolism remains an untested area toward cancer chemotherapy. Especially, inhibition of SPHK activity and www.biomolther.org

Open Access DOI: 10.4062/biomolther.2011.19.1.134

pISSN: 1976-9148 elSSN: 2005-4483

Copyright $\odot 2011$ The Korean Society of Applied Pharmacology
Received Dec 28, 2010 Revised Jan 21, 2011 Accepted Jan 21, 2011

\footnotetext{
*Corresponding Author

E-mail:ymleefn@hanmail.net

Tel: +82-43-261-2825, Fax: +82-43-268-2732
} 
subsequent reduction of S1P synthesis should have profound anti-proliferative effect on tumor cells because S1P is the most direct mitogenic messenger. This focus is substantiated by a recent demonstration that SPHK can directly transform the cells (Xia et al., 2000). This paper described the first demonstration that SPHK1 increases V12 RAS-dependent transformation of NIH3T3 fibroblasts to form fibrosarcoma cells when injected into immune compromised mice. Pharmacological studies have used three compounds to inhibit SPHK activity: $\mathrm{N}, \mathrm{N}$-dimethylsphingosne (DMS), D,L-threo-dihydrosphingosine and $\mathrm{N}, \mathrm{N}, \mathrm{N}$-trimethylsphingosine. However, these compounds are not specific inhibitors of SPHK as they are known to affect other kinases such as protein kinase C (Igarashi et al., 1989), sphingosine-dependent protein kinase (Megidish et al., 1995), 3-phosphoinositide-dependent kinase (King et al., 2000), and casein kinase (McDonald et al., 1991). In this report, we tested a series of synthetic pseudoceramides whether these compounds could regulate SPHK activity and found that $\mathrm{K} 6 \mathrm{PC}-5$, a hydrophobic pseudo-ceramide chemically named $\mathrm{N}$-(1,3-dihydroxyisopropyl)-2-hexyl-3-oxo-decanamide enhanced SPHK activity of F9-12 cell lysates where SPHK was highly expressed.

\section{MATERIALS AND METHODS}

\section{Materials}

The five synthetic pseudoceramides, (K-series; K6PC5, K6PC-7 and K10PC-5) (L-series; L6PC-5 and L6PC-7) were synthesized and were kindly supplied from Neopharm Co. (Daejeon, Korea). Sphingosine 1-phosphate (S1P) and d-erythro-sphingosine (So) were purchased from Biomol Research, Inc. (Plymouth Meeting, PA.,USA). $\mathrm{C}_{17}$-sphingosine $\left(C_{17}\right.$-So) and $C_{17}$ sphingosine 1-phosphate $\left(C_{17}\right.$-So1P) were obtained from Avanti Polar Lipids, Inc. (Alabastar, AL). Alkaline phosphatase (APase) (bovine intestinal mucosca type VII$\mathrm{T}), N, N$-dimethylsphingosine (DMS) and phorbol 12-myristate 13-acetate (PMA) were from Sigma (St. Louis, MO). Serum and culture media were obtained from Life Technologies, Inc. (Gaithersburg, MD). HPLC-grade acetonitrile was purchased from Mallinckrodt Baker, Inc. (Phillipsburg, NJ). o-phthalaldehyde (OPA) was obtained from Nacalai Tesque (Kyoto, Japan). All organic solvents and chemicals were of analytical grade.

\section{Cell culture and pseudoceramides treatment}

Mouse embryonal carcinoma F9-12 cells (SPHK overexpressed S1P lyase knocked-out) were kindly supplied by $\mathrm{Dr}$. A. Kihara in Hokkaido University, Japan. Cells were grown in Dulbecco modified Eagles medium (DMEM) containing 10\% (v/v) FBS and $1 \%$ penicillin-streptomycin in $0.1 \%$ gelatin-coated dishes. Cells were cultured at $37^{\circ} \mathrm{C}$ in a humidified $5 \% \mathrm{CO}_{2}$ atmosphere and routinely sub-cultured every other day using a solution of trypsin-EDTA from Life Technologies, Inc. (Gaithersburg, MD).

Pseudoceramides were dissolved in dimethyl sulfoxide (DMSO) and stored at $-20^{\circ} \mathrm{C}$ in $50 \mathrm{mM}$ stock solution. Ten microliters of stock solution were directly added to $10 \mathrm{ml}$ DMEM media of F9-12 cells growing dish. The cells were further incubated for $24 \mathrm{hr}$.

\section{Preparation of cell lysate}

Cells were immediately washed twice with ice-cold phos- phate-buffered saline and then scraped in $3 \mathrm{ml}$ of lysis buffer (1 mM PMSF, 1 x protease inhibitor cocktail, and $1 \mathrm{mM}$ dithiothreitol) after centrifugation at 10,000 RPM for $3 \mathrm{~min}$. The pellet lysated in $1 \mathrm{ml}$ assay buffer ( $12 \mathrm{mM} \beta$-glycerophosphate, $1 \mathrm{mM}$ sodium pyrophosphate, $5 \mathrm{mM}$ sodium fluoride, $1 \mathrm{mM}$ phenylmethylsulfonyl fluoride, $1 \mathrm{x}$ protease inhibitor cocktail, 5 mM sodium orthovanadate, $2 \mathrm{mM}$ dithiothreitol, $0.5 \mathrm{mM}$ 4-deoxypyridoxine) was then sonicated and centrifuged at 1,500 rpm for $3 \mathrm{~min}$ at $4^{\circ} \mathrm{C}$ and the resulting supernatant was determined the protein concentration by performing Bradford assay. The cell lysate was diluted to approximately $1 \mathrm{mg} / \mathrm{ml}$ total cell protein.

\section{SPHK activity assay}

Cells lysate (30 $\mu \mathrm{g}$ protein) was incubated in total volumes of $160 \mu \mathrm{l}$ with $10 \mu \mathrm{l}$ of $40 \mathrm{mM} \mathrm{ATP}$ in $200 \mathrm{mM} \mathrm{MgCl}$ and 10 $\mu \mathrm{l}$ of $100 \mu \mathrm{M} \mathrm{C}_{17}$-sphingosine in $5 \%$ Triton X-100. Incubations with cell lysates contained $5 \mathrm{mM} \mathrm{NaF}$ and $\mathrm{Na}_{3} \mathrm{VO}_{4}$, included as inhibitors of S1P phosphatase and lyase, respectively, to prevent potential degradation of formed $\mathrm{C}_{17}$-S1P. In case of in vitro assay, $10 \mu \mathrm{l}$ from $1 \mathrm{mM} \mathrm{K6PC-5}$ in DMSO was directly added to the cells lysate. The reaction started with $\mathrm{C}_{17}$-sphingosine addition to tube and was incubated for $20 \mathrm{~min}$ at $37^{\circ} \mathrm{C}$ for SPHK activation. The enzyme reaction was terminated by adding $20 \mu \mathrm{l}$ of $1.0 \mathrm{~N}-\mathrm{HCl}$ and ice-cold $0.8 \mathrm{ml} \mathrm{CHCl} /$ /Metha$\mathrm{nol} / \mathrm{HCl}(100: 200: 1, \mathrm{v} / \mathrm{v})$. The tube was gently mixed for $1 \mathrm{~min}$ after spiking $200 \mathrm{pmol}$ of $\mathrm{C}_{18}$-S1P as an internal standard. Then, $250 \mu \mathrm{l}$ of $\mathrm{CHCl}_{3}$ and $250 \mu \mathrm{l}$ of $2 \mathrm{M} \mathrm{NaCl}$ were added, and the mixture was vigorously vortexed for $10 \mathrm{~min}$. The tube was centrifuged for $4 \mathrm{~min}$ at $12,000 \mathrm{rpm}$ at $4^{\circ} \mathrm{C}$ and the aqueous upper phase was removed. The lower organic phase was transferred to a fresh tube and left on ice for $10 \mathrm{~min}$. Phospholylated $\mathrm{C}_{17}-\mathrm{S} 1 \mathrm{P}$ was extracted by adding $400 \mu \mathrm{l}$ of $\mathrm{H}_{2} \mathrm{O}$ and $40 \mu \mathrm{l}$ of $3 \mathrm{~N} \mathrm{NaOH}$. The tube was then vortexed for $10 \mathrm{~min}$ and centrifuged at 12,000 rpm for $4 \mathrm{~min}$. The alkaline aqueous phase containing S1P transferred to a fresh tube. The residual S1P in the $\mathrm{CHCl}_{3}$ phase were extracted twice with a $300 \mu \mathrm{l}$ of $\mathrm{H}_{2} \mathrm{O}$ and $10 \mu \mathrm{l}$ of $3 \mathrm{~N} \mathrm{NaOH}$. All of the aqueous fractions were then combined. The aqueous fraction of S1P extract was mixed thoroughly with $130 \mu \mathrm{l}$ of alkaline phosphatase (APase) reaction buffer (200 mM Tris- $\mathrm{HCl}\left(\mathrm{pH} \mathrm{7.4),} 75 \mathrm{mM} \mathrm{MgCl}_{2}\right.$ in $2 \mathrm{M}$ glycine buffer, $\mathrm{pH} 9.0$ ) and 50 units of APase enzyme for dephosphorylation. The tube was incubated at $37^{\circ} \mathrm{C}$ for $1 \mathrm{hr}$. The dephosphorylated sphingosine and $\mathrm{C}_{17}$-sphingosine were extracted twice with $500 \mu \mathrm{l}$ of $\mathrm{CHCl}_{3}$ and $300 \mu \mathrm{l}$ of $\mathrm{CHCl}_{3}$ then washed 3-times with alkaline water $(\mathrm{pH} 10.0)$. The washed $\mathrm{CHCl}_{3}$ phase was transferred to a fresh tube and dried completely under a nitrogen stream in a Pierce heating module.

\section{HPLC analysis}

The dried residues were dissolved again in $120 \mu$ ethanol, and incubated it at $65^{\circ} \mathrm{C}$ for $25 \mathrm{~min}$ and then labeled with $15 \mu \mathrm{l}$ OPA reagent (50 mg OPA, $1 \mathrm{ml}$ ethanol, $100 \mu \mathrm{l}$ 2-mercaptoethanol, and $50 \mathrm{ml} 3 \%(\mathrm{w} / \mathrm{v})$ boric acid solution). After incubation of the tubes for $40 \mathrm{~min}$ in dark room at room temperature, 100 $\mu \mathrm{l}$ aliquots was injected into the HPLC system which consisted of a Jasco (Tokyo, Japan) Model PU 9850 pump, Cosmosil 5C 18-AR II packed with Nova-Pak C18 (4.6 mm i.d. $\times 150 \mathrm{~mm}$ ), Jasco FP-920 fluorescence spectrophotometer (excitation $340 \mathrm{~nm}$ and emission $455 \mathrm{~nm}$ ) and Jasco autosampler. The isocratic mobile phase of $90 \%$ acetonitrile was pumped at a flow rate of $1 \mathrm{ml} / \mathrm{min}$. The resulting data and chromatographic 
profiles were evaluated using the Borwin system manager software (JMBS, France).

\section{XTT assay}

F9-12 cells were harvested, counted, and inoculated at 2.5 $\times 10^{3}$ cells $(100 \mu \mathrm{l})$ into 96 -well plates. After $24 \mathrm{hr}$, pseudoceramides dissolved in medium were applied (100 $\mu \mathrm{l})$ to triplicate culture wells, and cultures were incubated for $24 \mathrm{hr}$ at $37^{\circ} \mathrm{C}$. XTT (Sigma, St. Louis, MO) was prepared at $5 \mathrm{mg} / \mathrm{ml}$ in PBS and stored at $4^{\circ} \mathrm{C}$. After $24 \mathrm{hr}$ incubation, XTT was diluted 1 to 5 in medium without serum (containing $100 \mu$ activation solution), and $50 \mu \mathrm{l}$ were added to microculture wells. After 4 hr incubation at $37^{\circ} \mathrm{C}$, the plate was gently shaken to evenly distribute XTT dye in the wells. The absorbance at $540 \mathrm{~nm}$ was measured with a Molecular Devices mciroplate reader.

\section{Statistics}

All values were expressed as a mean \pm standard deviation (SD). Differences between treatments were analyzed statistically by unpaired Student's t-test. Differences with $p<0.01$ were defined as statistically significant.

\section{RESULTS}

\section{Design of synthetic pseudoceramides for the regulation of SPHK activity}

Five pseudoceramides showing closely related structure to natural ceramides were synthesized by NeoPharm Co. Three pseudoceramides (K-series) contains a ketone group, two hydroxyl groups, two short alkyl groups, and an amide<smiles>[R2]C(C(=O)C=[Y4]C)C(=O)NC(CO)CO</smiles>

K6PC-5<smiles>[R2]C(C(=O)COC)C(=O)NC(C)(CO)CO</smiles>

K6PC- ?<smiles>[R2]C(C(=O)NC(CO)CO)C(O)CC(C)C</smiles>

L6PC-5<smiles>[R2]C(C(=O)NC(C)(CO)CO)C(O)C[Y4]([H])=O</smiles>

L6PC-7<smiles>[R2]C(C(=O)CCC)C(=O)CNC(CO)CO</smiles>

K10PC-5

Fig. 1. Chemical structure of pseudoceramides. R2 contains hexyl group. K-series contains a ketone group while L-series contains a hydroxyl group. linkage with a chemical name of $\mathrm{N}-(1,3-$ dihydroxyisopropyl)2-hexyl-3-oxo-decanamide. Other two pseudoceramides (L-series) contains three hydroxyl groups, two short alkyl groups, and an amide linkage with a chemical name of $\mathrm{N}-(1,3-$ dihydroxyisopropyl)-2-hexyl-3-hydroxy-decanamide (Fig. 1). Five pseudoceramides were commonly designed to contain a 1,3-dihydroxyisopropyl group, which possibly provides phosphorylation site by SPHK activation.

\section{Effect of synthetic pseudoceramides on SPHK activity in F9-12 cells}

Previously, PMA has been well used as a typical SPHK activation marker in a cell-based assay system. SPHK activity in F9-12 cells was 1.5 -fold activated in $1 \mathrm{hr}$ treatment, indicating that F9-12 cell-based system is a reliable tool to search for SPHK regulators. The internal SPHK activities in F9-12 cells were relatively high because F9-12 cells were SPHK overexpressed mutant selected from a colony resistant to G418 $\left(\right.$ Geneticin $\left.^{\circledR}\right)$ treatment. Therefore, SPHK activity with $10 \mathrm{ul}$ of DMSO treatment (control) was measured $780 \mathrm{pmol} / \mathrm{min} / \mathrm{mg}$ protein. Pseudoceramide K10PC-5 greatly inhibited SPHK activity compared to other pseudoceramides (Fig. 2). This unusual inhibition by K10PC-5 might be contributed to the existence of relatively long chain of 3-oxo-tetradecanamide. L6PC-7 which containing 2-methyl group on N-(1,3-dihydroxyisopropyl) structure also mildly inhibited SPHK activity. Interestingly, K6PC-5 was seem to activate SPHK activity, suggesting that two hydroxyl sites in $\mathrm{N}$-(1,3-dihydroxyisopropyl) structure may activate SPHK through providing phosphorylation site like as a major substrate, sphingosine.

\section{Inhibition of SPHK activity by K10PC-5}

K10PC-5 strongly inhibited SPHK activity from the concentration above $20 \mu \mathrm{M}$, while $10 \mathrm{uM}$ did not show any inhibition on SPHK activity (Fig. 3A). The $88 \%$ of SPHK activity was reduced by $20 \mu \mathrm{M} \mathrm{K10PC-5,} \mathrm{suggesting} \mathrm{that} \mathrm{K10PC-5} \mathrm{will} \mathrm{be} \mathrm{a}$ pharmacological candidate for SPHK enzyme inhibitor which may induce cancer cells death. Next, inhibition of SPHK activ-

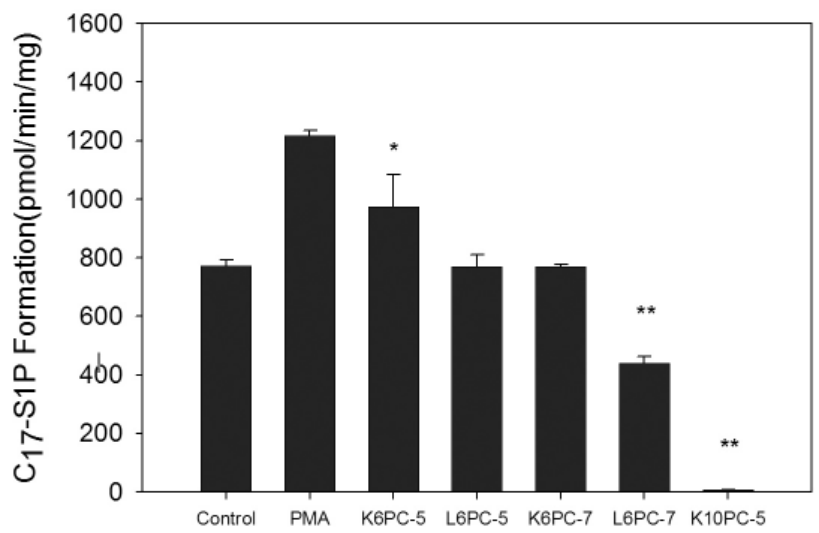

Fig. 2. Effect of pseudo-ceramides on SPHK activity in F9-12 cells. F9-12 cells were treated with $300 \mathrm{nM}$ of PMA and incubated for $1 \mathrm{hr}$. The C17-S1P formation by PMA treatment used as a positive SPHK activation biomarker. Five pseudo-ceramides, K6PC5, L6PC-5, K6PC-7, L6PC-7 and K10PC-5 were treated with the concentration of $50 \mu \mathrm{M}$ in F9-12 cells and further incubated for $24 \mathrm{hr}$. Control means $10 \mu \mathrm{l}$ DMSO treatment. Data are shown as mean \pm S.D. ${ }^{*} p<0.05,{ }^{* *} p<0.01$ compare to control group. 
A

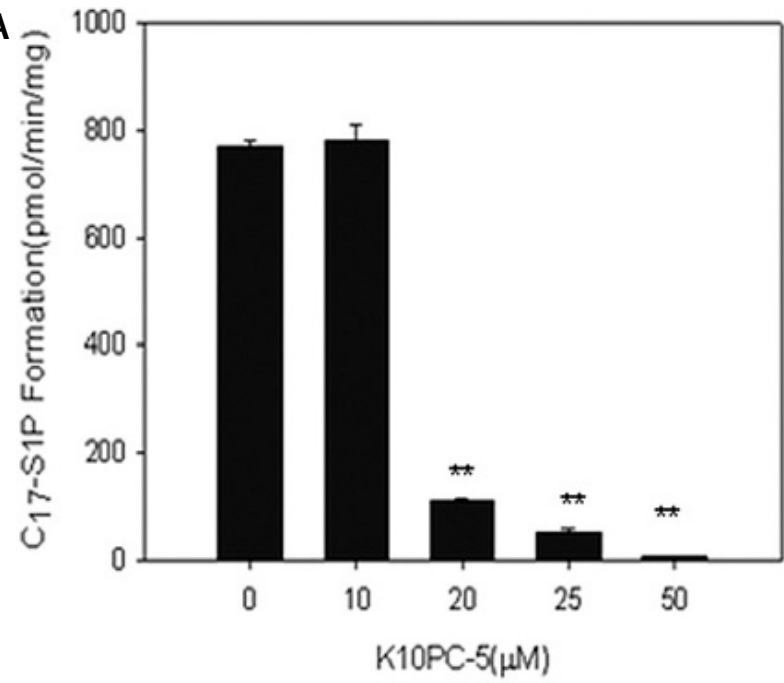

B

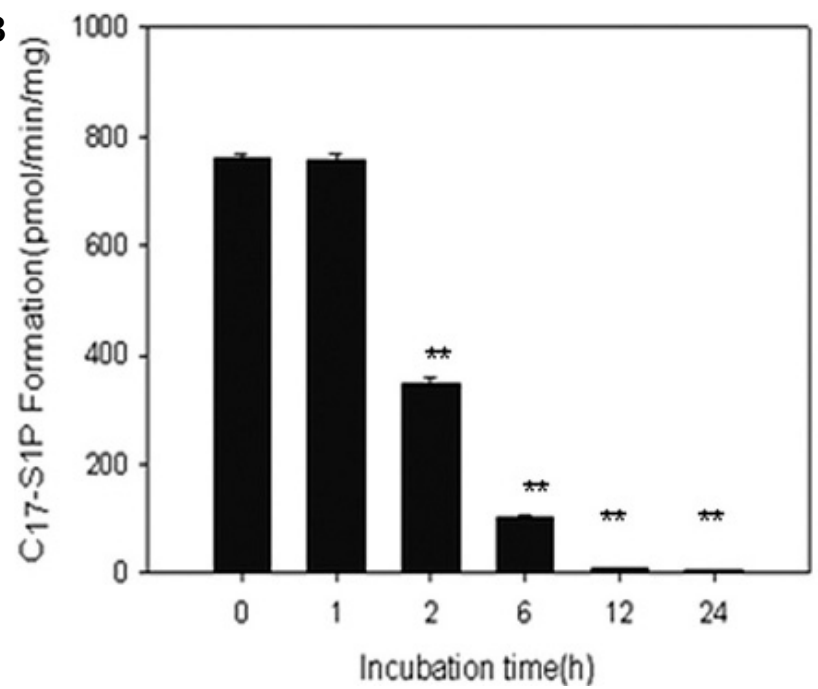

Fig. 3. Inhibition of SPHK activity by K10PC-5. A) F9-12 cells were treated with indicated concentrations $(0,10,20,25,50 \mu \mathrm{M})$ of $\mathrm{K} 10 \mathrm{PC}-5$ and then incubated for $24 \mathrm{hr}$. B) F9-12 cells was treated with $50 \mu \mathrm{M} \mathrm{K10PC}-5$ and incubated with indicated hours. The SPHK enzyme activity was measured. ${ }^{* *} p<0.01$ compare to control group.

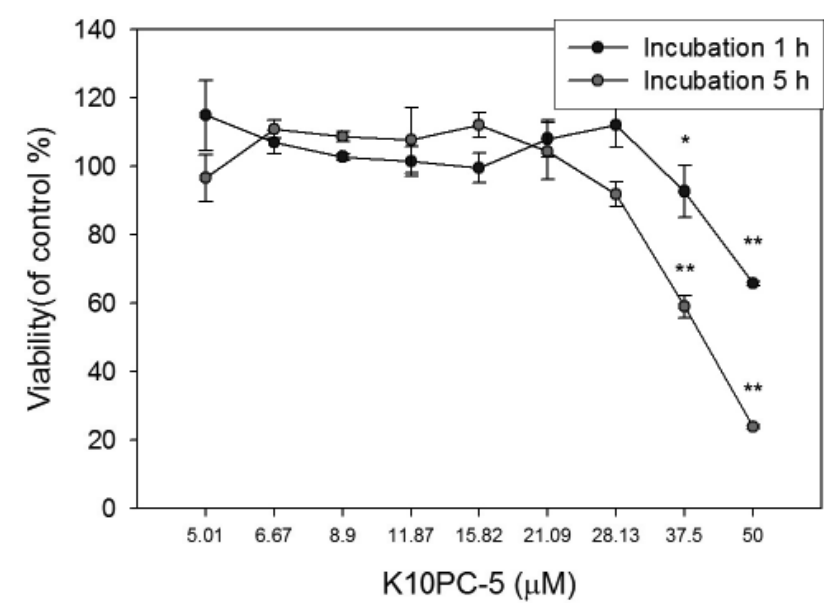

Fig. 4. Effect of K10PC-5 on F9-12 cells viability. F9-12 cells in $2.5 \times 10^{4}$ cells $/ \mathrm{ml}$ were seeded. After $24 \mathrm{hr}$ incubation, F9-12 cells were treated with the indicated concentrations $(5.01,6.67,8.9$ $11.87,15.82,21.09,28.13,37.5,50 \mu \mathrm{M})$ of K10PC-5 and then incubated for $1 \mathrm{hr}$ or $5 \mathrm{hr}$. XTT assay were applied for measuring the cell viability. Black circle represents the $1 \mathrm{hr}$ incubation at the given concentrations of K10PC-5, and grey circle represents the 5 $\mathrm{hr}$ incubation. Data are shown as mean \pm S.D. ${ }^{*} p<0.05,{ }^{* *} p<0.01$ compare to control group.

ity by $\mathrm{K} 10 \mathrm{PC}-5$ was measured to find the minimal time point by varying the incubation time. As shown in Fig. 3B, K10PC-5 $(50 \mu \mathrm{M})$ started to inhibit $50 \%$ of C17-S1P formation within 2 $\mathrm{hr}$. These results indicated that K10PC-5 has a strong potency to inhibit SPHK activity.

In short hour treatment of K10PC- 5 from $1 \mathrm{hr}$ to $5 \mathrm{hr}$, cell viability was not changed below the concentration of $30 \mu \mathrm{M}$ (Fig. 4). However, in high concentration of K19PC-5 cell viability was abruptly reduced in a dose-dependent manner, suggesting that the inhibition of SPHK activity might trigger a variety of death signals.

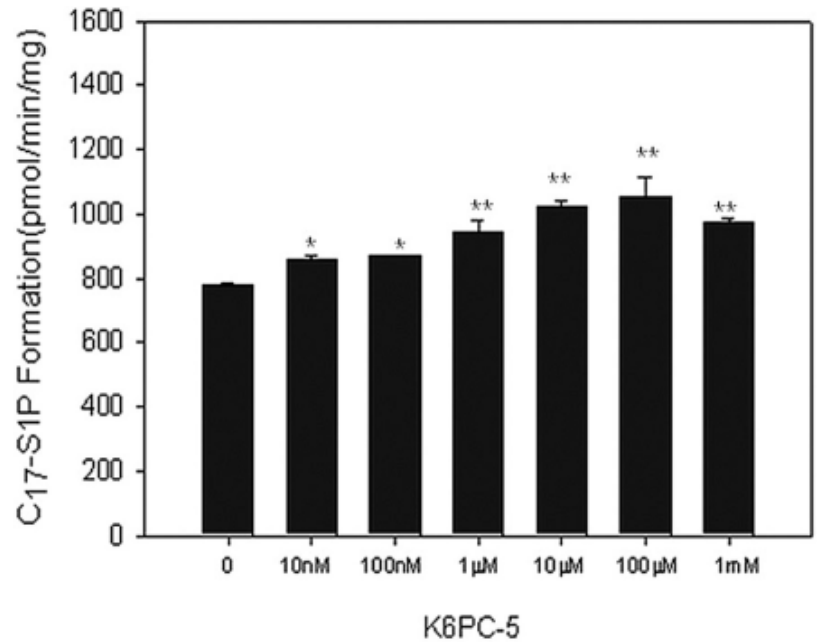

Fig. 5. Activation of SPHK activity in cell lysate by K6PC-5. Cell lysate was treated with the indicated concentrations $(0,10 \mathrm{nM}$, $100 \mathrm{nM}, 1 \mu \mathrm{M}, 10 \mu \mathrm{M}, 100 \mu \mathrm{M}$ and $1 \mu \mathrm{mM}$ ) of K6PC-5, then incubated for $20 \mathrm{~min}$ at $37^{\circ} \mathrm{C}$. Data are shown as mean \pm S.D. ${ }^{*} p<0.05$, ${ }^{* *} p<0.01$ compare to control group.

\section{Specific activation of SPHK activity by K6PC-5}

Meanwhile, K6PC-5 compound which has a relatively short chain 3-oxo-decanamide moiety was well dissolved in culture medium. As shown in Fig. 1, K6PC-5 showed a unique character to enhance SPHK activity in cell-based assay. To clarify SPHK regulation specificity of K6PC-5 in cell-free system, cell lysate was incubated with various concentrations of K6PC-5 for $20 \mathrm{~min}$ at $37^{\circ} \mathrm{C}$. In cell-free system, K6PC-5 also activated SPHK activity in a dose dependent manner, although a high concentration of $1.0 \mathrm{mM} \mathrm{K6PC-5}$ mildly activated SPHK activity (Fig. 5).

DMS has been well known as a strong SPHK inhibitor in 


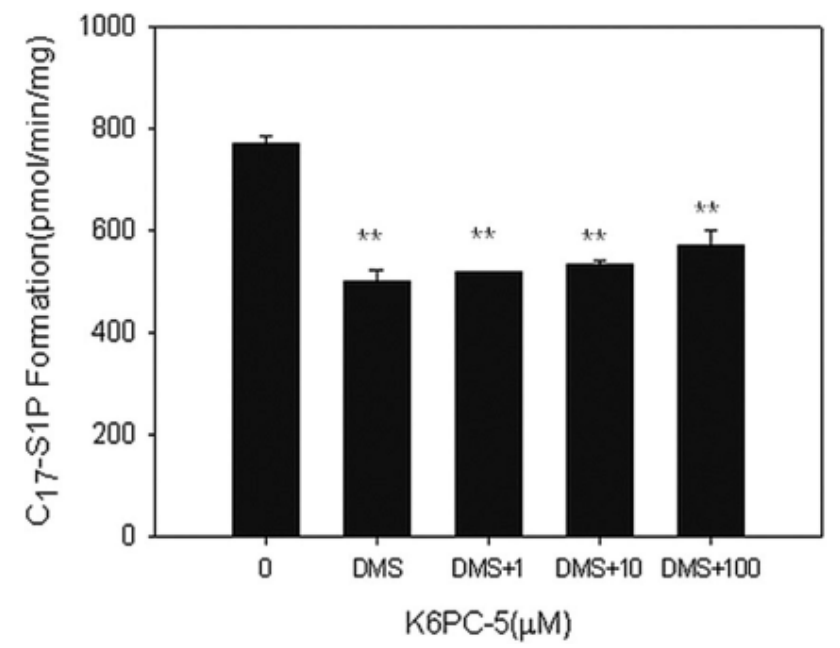

Fig. 6. Effect of K6PC-5 on SPHK activity during SPHK inhibition by $50 \mu \mathrm{M}$ DMS. Cell lysate was co-treated with $50 \mu \mathrm{M}$ DMS and three different concentrations (1, 10 and $100 \mu \mathrm{M})$ of K6PC- 5 for 20 min. Data are shown as mean \pm S.D. ${ }^{* *} p<0.01$ compare to control group.

vivo or in vitro system and still have used to be a control compound. In this experiment, K6PC-5 were treated with $50 \mu \mathrm{M}$ DMS in the indicated different concentrations for measuring the SPHK activating ability by K6PC-5. DMS only treatment inhibited ca. $40 \%$ of total SPHK activity. However, by co-treatment of $100 \mu \mathrm{M}$ K6PC-5 with $50 \mu \mathrm{M}$ DMS, reduced-SPHK activity was slightly recovered in a dose dependent manner (Fig. 6).

\section{DISCUSSION}

We newly synthesized five chemically related compounds which their representative compound, K6PC-5 containing a ketone group, two hydroxyl groups, two short alkyl groups, and an amide linkage, characterized as a "pseudo-ceramide" backbone with a chemical name of $\mathrm{N}$-(1,3-dihydroxyisopropyl)2-hexyl-3-oxo-decanamide. K6PC-5 was originally reported to induce the keratinocyte differentiation (Kwon et al., 2007).

The synthesis of pseudoceramides was basically designed on the fact that the reduction of carbon chain length may reduce the molecular size which gives similar hydrophobicity to sphingosine, a SPHK substrate. In addition, 1,3-dihydroxyisopropyl structure may provide the double phosphorylation sites to SPHK enzyme. Indeed, FTY720, a synthetic sphingosinelike compound containing a 1,3-dihydroxyisopropyl group was well phosphorylated by SPHK activation (Billich et al., 2003). The methyl moiety in 1,3-dihydroxyisopropyl group of K6PC-7 and L6PC-7 may not be a significant factor for phosphorylation, rather be a disturbance factor for phosphorylation (Fig. 2).

In the presence of increased hydrophobicity by the extension of chain length from 3-oxo-decanamide to 3-oxo-tetradecanamide, K10PC-5 greatly inhibited SPHK (Fig. 3). This inhibition also influenced on cell viability after the treatment of $50 \mu \mathrm{M} \mathrm{K} 10 \mathrm{PC}-5$ in $1 \mathrm{hr}$ (Fig. 4). However, this cell-based assay did not exclude the possibility that K10PC-5 possibly trig- gers the multiple set of cell death signaling pathway. Recently, SPHK was suggested as a new drug target for the treatment of cancer and many chronic diseases which is related to inflammatory responses and already some of SPHK specific inhibitors were developing for chemotherapy resistant cancer therapy (Hengst et al., 2010; Sharma et al., 2010). In this initial study, we developed a lipid drug candidate for cancer treatment showing an enhanced solubility which may be a critical factor for toxicological evaluation and further drug development process.

K6PC-5 was found to activate SPHK in cell-based assay (Fig. 1). In general, SPHK activation is triggered by various growth factors, for example, VEGF, PDGF and EGF or TNFa signals (Pyne and Pyne, 2008). Therefore, K6PC-5 may also trigger the multiple set of cell growth signaling pathway. To exclude this possibility, we measured SPHK activation by K6PC-5 in cell-free assay system. Interestingly, $10 \mu \mathrm{M} \mathrm{K6PC-}$ 5 showed 1.3-fold increase of SPHK activity which is comparable to the SPHK activation by $300 \mathrm{nM}$ TNF-a treatment (Xia et al., 1999). Although a high concentration of K6PC-5 was required to overcome the inhibition by a competitive SPHK inhibitor DMS, K6PC-5 might be a direct SPHK activator. These data suggested that a synthetic pseudo-ceramide mimics the physiological role of S1P, which produced by SPHK activation and worked as either a second messenger or a ligand of S1P receptors.

FTY720 (fingolimid) having 1,3-dihydroxyisopropyl structure was synthesized and has been developed as an immunosuppressant, which was known to inhibit lymphocyte trafficking from lymph node to blood stream (Brinkmann, 2009). FTY720 has also inhibited SPHK and specifically phosphorylated by SPHK2 to bind to S1P receptors (Paugh et al., 2003). Recently, FTY720 was developed as a drug for multiple sclerosis (Walter and Fassbender, 2010). Therefore, synthetic strategy to develop SPHK inhibitor or activator will derive a new therapeutic candidate which controls cell death and cell proliferation. The finding the success of SPHK inhibition in cancer and a range of other disease models were demonstrated that the inhibitors of the SPHK pathway promotes the continued interest in targeting the SPHK for therapeutic benefit (Pitman and Pitson, 2010).

Collectively, K10PC-5 and K6PC-5 regulated SPHK activity in cell-based assay and particularly SPHK was activated by K6PC-5, which suggesting the possibility of K6PC-5 working as a S1P mimicking second messenger or a ligand agonist for S1P receptors as like FTY720.

\section{ACKNOWLEDGMENTS}

This research was supported by the Chungbuk National University research grants in 2008.

\section{REFERENCES}

Billich, A., Bornancin, F., Dévay, P., Mechtcheriakova, D., Urtz, N. and Baumruker, T. (2003) Phosphorylation of the immunomodulatory drug FTY720 by sphingosine kinases. J. Biol. Chem. 278, 4740847415.

Brinkmann, V. (2009) FTY720 (fingolimod) in Multiple Sclerosis: therapeutic effects in the immune and the central nervous system. $\mathrm{Br}$. J. Pharmacol. 158, 1173-1182. 
Claus, R., Russwurm, S., Meisner, M., Kinscherf, R. and Deigner, H. P. (2000) Modulation of the ceramide level, a novel therapeutic concept? Curr. Drug Targets 1, 185-205.

Hannun, Y. A. and Obeid, L. M. (1995) Ceramide: an intracellular signal for apoptosis. Trends Biochem. Sci. 20, 73-77.

Hengst, J. A., Wang, X., Sk, U. H., Sharma, A. K., Amin, S. and Yun, J. K. (2010) Development of a sphingosine kinase 1 specific smallmolecule inhibitor. Bioorg. Med. Chem. Lett. 20, 7498-74502.

Hla, T., Lee, M. J., Ancellin, N., Paik, J. H. and Kluk, M. J. (2001) Lysophospholipids-receptor revelations. Science 294, 1875-1878

Igarashi, Y., Hakomori, S., Toyokuni, T., Dean, B., Fujita, S., Sugimoto, M., Ogawa, T., Ghendy, K. and Racker, E. (1989) Effect of chemically well-defined sphingosine and its $\mathrm{N}$-methyl derivatives on protein kinase $C$ and src kinase activities. Biochemistry 28, 67966800

Johnson, K. R., Becker, K. P., Facchinetti, M. M., Hannun, Y. A. and Obeid, L. M. (2002) PKC-dependent activation of sphingosine kinase 1 and translocation to the plasma membrane. J. Biol. Chem. 38, 35257-35262.

King, C. C., Zenke, F. T., Dawson, P. E., Dutil, E. M., Newton, A. C. Hemmings, B. A., and Bokoch, G. M. (2000) Sphingosine is a novel activator of 3-phosphoinositide-dependent kinase 1. J. Biol. Chem. 275, 18108-18113.

Kluk, M. J. and Hla, T. (2002) Signaling of sphingosine-1-phosphate via the SIP/EDG-family of G-protein-coupled receptors. Biochim. Biophys. Acta. 1582, 72-80.

Kwon, Y. B., Kim, C. D., Youm, J. K., Gwak, H. S., Park, B. D., Lee, S. H., Jeon S., Kim, B. J., Seo, Y. J., Park, J. K. and Lee, J. H. (2007) Novel synthetic ceramide derivatives increase intracellular calcium levels and promote epidermal keratinocyte differentiation. J. Lipid Res. 48,1936-1943

Lee, M. J., Van Brocklyn, J. R., Thangada, S., Liu, C. H., Hand, A. R., Menzeleev, R., Spiegel, S. and Hla, T. (1996) Sphingosine 1-phosphate as a ligand for the G-protein-coupled receptor EDG-1. Science 279, 1552-1555.

Maceyka, M., Payne, S.G., Milstien, S. and Spiegel, S. (2002) Sphingosine kinase, sphingosine-1-phosphate, and apoptosis. Biochim. Biophys. Acta. 1585, 193-201.

McDonald, O. B., Hannun, Y. A., Reynolds, C. H. and Sahyoun, N (1991) Activation of casein kinase II by sphingosine. J. Biol. Chem. 266, 21773-21776
Megidish, T., White, T., Takio, K., Titani, K., Igarashi, Y. and Hakomori, S. (1995) The signal modulator protein 14-3-3 is a target of sphingosine- or N,N-dimethylsphingosine-dependent kinase in 3T3 (A31) cells. Biochem. Biophys. Res. Commun. 216, 739-747.

Ogretmen, B. and Hannun, Y. A. (2001) Updates on functions of ceramide in chemotherapy-induced cell death and in multidrug resistance. Drug Resist. Updat. 4, 368-377.

Olivera, A., Rosenfeldt, H.M., Bektas, M., Wang, F., Ishii, I., Chun, J., Milstien, S. and Spiegel, S. (2003) Sphingosine kinase type 1 induces G12/13-mediated stress fiber formation, yet promotes growth and survival independent of $\mathrm{G}$ protein-coupled receptors. $J$. Biol. Chem. 278, 46452-46460.

Paugh, S. W., Payne, S. G., Barbour, S. E., Milstien, S. and Spiegel, S. (2003) The immunosuppressant FTY720 is phosphorylated by sphingosine kinase type 2. FEBS Lett. 554, 189-193.

Pitman, M. R. and Pitson S. M. (2010) Inhibitors of the sphingosine kinase pathway as potential therapeutics. Curr. Cancer Drug Targets 10, 354-367.

Pyne, S. and Pyne, N. J. (2000) Sphingosine 1-phosphate signaling in mammalian cells. Biochem. J. 349, 385-402.

Pyne, N. J. and Pyne, S. (2008) Sphingosine 1-phosphate, lysophosphatidic acid and growth factor signaling and termination. Biochim. Biophys. Acta. 1781, 467-476.

Sharma, A. K., Sk, U. H., Gimbor, M. A., Hengst, J. A., Wang, X., Yun, J. and Amin, S. (2010) Synthesis and bioactivity of sphingosine kinase inhibitors and their novel aspirinyl conjugated analogs. Eur. J. Med. Chem. 45, 4149-4156.

Spiegel, S., English, D. and Milstien, S. (2002) Sphingosine 1-phosphate signaling: providing cells with a sense of direction. Trends Cell Biol. 12, 236-242.

Walter S., and Fassbender K. (2010) Spingolipids in Multiple Sclerosis. Cell Physiol. Biochem. 26, 49-56.

Watterson, K., Sankala, H., Milstien, S. and Spiegel, S. (2003) Pleiotropic actions of sphingosine-1-phosphate. Prog. Lipid Res. 42, 344-357.

Xia, P., Wang, L., Gamble J.R. and Vadas, M.A. (1999) Activation of sphingosine kinase by tumor necrosis factor-alpha inhibits apoptosis in human endothelial cells. J. Biol. Chem. 274, 34499-34505.

Xia, P., Gamble, J. R., Wang, L., Pitson, S. M., Moretti, P. A., Wattenberg, B. W., D'Andrea, R. J. and Vadas, M. A. (2000) An oncogenic role of sphingosine kinase. Curr. Biol. 10, 1527-1530. 